\title{
CIRCULAÇÃO DE OBRAS ARQUIVÍSTICAS FRANCESAS NO BRASIL
}

\section{CIRCULATION OF FRENCH ARCHIVAL WORKS IN BRAZIL}

\author{
Angélica Alves da Cunha Marquesa \\ José Mauro Gouveia Medeiros ${ }^{b}$
}

\begin{abstract}
RESUMO
Introdução: Este artigo integra um amplo projeto de pesquisa sobre a trajetória da internacionalização da Arquivologia e a sua institucionalização como disciplina no Brasil. Objetivo: Investigar as contribuições francesas para a Arquivologia brasileira, por meio da circulação de obras arquivísticas francesas no Brasil. Metodologia: Pesquisa de abordagem quali-quantitativa; exploratória e descritiva, quanto aos seus objetivos; bibliográfica e documental, por meio de um estudo bibliométrico comparativo dos livros sobre arquivos e/ou Arquivologia, identificados no catálogo on-line da biblioteca do Arquivo Nacional. Resultados: A análise de 334 obras arquivísticas identificadas como livros nesse catálogo apontou que a maioria dessas obras foi publicada na década de 1980, em Paris e em francês. Tratam-se predominantemente de instrumentos de pesquisa, livros e publicações técnicas produzidos por autores de nacionalidade francesa ou que tenham sede no país, no caso de instituições internacionais. Conclusões: $O$ universo analisado diz respeito a obras recentes, sobre questões arquivísticas diversas, inclusive na perspectiva internacional, o que pode justificar a sua circulação no Brasil. Não foi encontrada uma razão evidente para a aquisição de uma quantidade significativa de instrumentos de pesquisa de instituições francesas, pelo Arquivo Nacional. Ainda que a instituição brasileira se inspire na francesa, há outros tipos de obras que merecem investimento da instituição tendo em vista a referência do pensamento arquivístico francês, inclusive na contemporaneidade.
\end{abstract}

Descritores: Arquivologia. Bibliografia arquivística. Livros arquivísticos. Circulação de obras francesas.

\section{INTRODUÇÃO}

Há nove anos, em sua tese de doutorado sobre as interlocuções entre a Arquivologia internacional e nacional, Marques (2011) realizou um mapeamento

\footnotetext{
a Doutora em Ciência da Informação pela Universidade de Brasília (UnB). Docente de Arquivologia da Universidade de Brasília (UnB). E-mail: angelicacunha@unb.br

b Doutorando em Ciência da Informação da Universidade de Brasília (UnB). Arquivista, bibliotecário e mestre pela Universidade de Brasília (UnB). e E-mail: medeirosjmg@gmail.com
} 
das obras arquivísticas publicadas no exterior e no Brasil, de autores brasileiros e estrangeiros, além de traduções brasileiras para o português, no catálogo online da biblioteca "Maria Beatriz Nascimento" do Arquivo Nacional do Brasil (AN). Como esclarece a autora, a sua opção metodológica contemplou o rico acervo de uma das bibliotecas brasileiras mais especializadas em temáticas arquivísticas:

A opção pela pesquisa nessa biblioteca deve-se ao fato de que a instituição mantém-se atualizada quanto à bibliografia arquivística internacional, decorrente das suas traduções de obras estrangeiras e da participação de seus servidores e diretores em instâncias de organizações internacionais, tais como o [International Council on Archives] ICA e a [Asociación Latinoamericana de Archivos] ALA. (MARQUES, 2011, p. 37).

Em sua pesquisa, a estudiosa identificou 1.515 referências bibliográficas arquivísticas, que foram filtradas até que ela chegasse aos manuais operacionais e científicos da área, que contemplaram 310 livros (MARQUES, 2011).

Este artigo faz parte de um projeto de pesquisa sobre a trajetória da internacionalização da Arquivologia e a sua institucionalização como disciplina no Brasil, cujo objetivo é investigar as contribuições francesas para a Arquivologia brasileira'. Nele, retomamos os resultados do estudo de Marques (2011), buscando atualizá-los a partir da metodologia da autora, com alguns ajustes para mapear a circulação de obras arquivísticas francesas no Brasil, isto é, livros que tenham temáticas sobre os arquivos e/ou a Arquivologia.

Nessa perspectiva, é importante lembrar que, no final da década de 1950, - AN começou a editar uma série de publicações técnicas que contemplou traduções de obras internacionais de referência. Das 45 publicações identificadas por Fonseca (1988), quinze eram brasileiras e, mais da metade, norte-americanas ou francesas. Esses resultados se aproximam daqueles da pesquisa de Marques (2011), nos quais a autora pode observar a predominância dos Estados Unidos e da França no ranking de países de publicação das obras arquivísticas estrangeiras identificadas na biblioteca do AN.

Tendo em vista o objetivo proposto, apresentamos os resultados da

\footnotetext{
1 Este projeto de pesquisa foi financiado pela Coordenação de Aperfeiçoamento de Pessoal de Nível Superior (CAPES) - processo n. 23038.009426/2012-49.
} 
pesquisa que realizamos no catálogo on-line da mesma biblioteca, comparados com aqueles da referida pesquisa - doravante identificada pelo ano de 2011 conforme os procedimentos e referenciais metodológicos descritos na próxima seção.

\section{PROCEDIMENTOS E REFERENCIAIS METODOLÓGICOS}

Este artigo foi desenvolvido por meio de uma pesquisa de abordagem quali-quantitativa; exploratória e descritiva, quanto aos seus objetivos; bibliográfica e documental, por meio de um estudo bibliométrico comparativo com a pesquisa de Marques (2011). Para tal, levou em consideração alguns referenciais teóricos relacionados à Bibliometria.

E. Wyndham Hulme, em 1923 apresentou o termo "bibliografia estatística", que mais tarde seria conhecida como "Bibliometria", a partir do "Traité de Documentacion", obra publicada por Paul Otlet em 1934 (ARAÚJO, 2006). Trata-se de uma área de estudos que "se dedica aos aspectos quantitativos da produção, disseminação e uso da informação registrada" e que faz uso de "métodos matemáticos e estatísticos", podendo "ser classificados segundo as fontes de dados que constituem a base da análise, ou segundo os propósitos ou aplicações dessas mesmas análises" (LARA, 2006). O princípio da Bibliometria consiste, assim, em analisar a atividade científica ou técnica pelos estudos quantitativos das publicações (ZAUITH; HAYASHI, 2013). Seu objetivo é analisar a produção científica, colocando-se como um instrumento importante na gestão da informação registrada, que se encontra disponível para os pesquisadores das diversas áreas do conhecimento (ROSTIROLLA, 2014). Nesse sentido, os resultados da nossa análise bibliométrica poderão auxiliar na compreensão do comportamento de desenvolvimento da ciência, mais especificamente da Arquivologia.

Na pesquisa realizada no catálogo on-line da biblioteca do $\mathrm{AN}^{2}$, Marques utilizou vários descritores para buscar obras arquivísticas brasileiras e

\footnotetext{
2 Pesquisa realizada no seguinte endereço eletrônico: http://www.an.gov.br/scripts/sysbibli/sysportal.exe/index\#0, entre 28 de abril e 04 de maio de 2010.
} 
estrangeiras, além daquelas traduzidas para o português no Brasil. Como filtros para a recuperação dos materiais descritos como livros, livros técnicos e livros raros, ela usou os termos: arquivologia, arquivística(o), arquivo(s), archivistique, archival science, archivística, archivología, archives, archivo, arquivista, archiviste, archivero e archivólogo, conforme Tabela 1.

Tabela 1 - Descritores utilizados na pesquisa (2011)

\begin{tabular}{ccc}
\hline DESCRITOR & F & $\%$ \\
\hline Arquivos & 1397 & 66,46 \\
Arquivo & 265 & 12,61 \\
Arquivologia & 126 & 5,99 \\
arquivística & 125 & 5,95 \\
archivo & 75 & 3,57 \\
archivística & 44 & 2,09 \\
archives & 41 & 1,95 \\
archivistique & 12 & 0,57 \\
arquivístico & 11 & 0,52 \\
archivología & 4 & 0,19 \\
archiviste & 2 & 0,10 \\
archival science & 0 & 0 \\
arquivista & 0 & 0 \\
archivero & 0 & 0 \\
archivólogo & 0 & 0 \\
\hline TOTAL & 2.102 & 100
\end{tabular}

Fonte: (MARQUES, 2011, p. 254-255).

A partir desses filtros, a pesquisadora chegou a 2.102 referências bibliográficas, das quais excluiu os resultados repetidos, reduzindo o universo inicial a 1.517 referências bibliográficas arquivísticas, ao identificar: a) 1.001 obras estrangeiras; b) 502 brasileiras; c) duas publicadas simultaneamente no País e no exterior; e d) doze traduções. Das 1.001 obras estrangeiras mapeadas, foram selecionadas 310 livros que diziam respeito a obras arquivísticas diversas, excluindo-se: a) as obras de instituições arquivísticas ${ }^{3}$; b) aquelas referentes a cursos de formação/aperfeiçoamento profissional ${ }^{4} \mathrm{e}$ a eventos; $\mathrm{c}$ ) normas $\mathrm{e}$ diretrizes internacionais; d) instrumentos de pesquisa (guias, inventários, repertórios, catálogos, etc.); e) legislações nacionais; f) estudos do projeto

\footnotetext{
${ }^{3}$ Obras sobre a história dessas instituições e demais documentos internos (relatórios, projetos, reformas institucionais, legislação, eventos, notícias, diretrizes, estudos, diagnósticos, cooperação técnica e políticas).

${ }^{4}$ Como, por exemplo, programas e prospectos desses cursos.
} 
Records and Archives Management Program (RAMP) da Organização das Nações Unidas para a Educação, a Ciência e a Cultura (UNESCO); e g) obras sobre a terminologia arquivística e outras obras que eram da História, ainda que recuperadas como arquivísticas.

Em nossa pesquisa, realizada no catálogo on-line da mesma biblioteca ${ }^{5}$, entre julho de 2018 e maio de 2019, recuperamos 27.968 referências bibliográficas (Tabela 2), a partir dos mesmos descritores utilizados por Marques (2011). Esse universo foi reduzido a 3.449 obras, mediante a seleção de obras identificadas pelo AN como "livro" ou "livro raro", sobre as quais não sabemos se a instituição considera as definições a seguir para a sua classificação dessas obras.

Tabela 2 - Descritores utilizados na pesquisa (2018)

\begin{tabular}{ccc}
\hline DESCRITOR & F & $\%$ \\
\hline arquivos & 9030 & 32,29 \\
arquivo & 6799 & 24,31 \\
archivo & 3702 & 13,24 \\
archives & 2987 & 10,68 \\
arquivística & 2135 & 7,63 \\
arquivologia & 1617 & 5,78 \\
archivistique & 488 & 1,74 \\
archival science & 488 & 1,74 \\
archivística & 416 & 1,49 \\
arquivístico & 121 & 0,43 \\
archiviste & 81 & 0,29 \\
arquivista & 48 & 0,17 \\
archivero & 32 & 0,11 \\
archivología & 24 & 0,09 \\
archivólogo & 0 & 0 \\
\hline TOTAL & 27968 & 100 \\
\hline
\end{tabular}

Fonte: Elaboração própria.

O livro pode ser definido como "documento, formado pela reunião de folhas ou cadernos, geralmente impressos e constituindo uma unidade bibliográfica" ou "publicação avulsa, contendo no mínimo 50 páginas impressas, grampeadas, coladas ou costuradas e revestida de capa" (CUNHA; CAVALCANTI, 2008, p. 231).

\footnotetext{
${ }^{5}$ Disponível em:

http://biblioteca.an.gov.br/scripts/bnportal/bnportal.exe/index\#acao=geral\&uv=vbibltip 1 :tipos:d escricao;vbiblunio:unidades:nome_unidade;vbiblidi0:idiomas:nome;vbiblaco0:areas:nome\&ali as=geral\&xsl=home. Acesso em 01 jul. 2019.
} 
Os livros raros, por sua vez, são difíceis de serem definidos em razão de duas situações que precisam ser consideradas:

[...] é impossível predeterminar as características de um livro raro, porque cada livro é um universo restrito de manifestações culturais - originais e acrescentadas; e é difícil discernir sobre características postas em evidência, quando se tenta provar a raridade de um livro - os argumentos são frágeis, baseados no "inquestionável" pressuposto da antiguidade. (PINHEIRO, 2009, p. 31).

De forma simples, o livro raro pode ser apresentado como

[...] aquele difícil de encontrar por ser muito antigo, ou por tratarse de um exemplar manuscrito, ou ainda por ter pertencido a uma personalidade de reconhecida projeção e influência no país e mesmo fora dele (por exemplo: imperadores, reis, presidentes), ou reconhecidamente importantes para determinada área do conhecimento (física, biologia, matemática e outras). (RODRIGUES, 2006, p. 115).

Para o alcance do objetivo deste trabalho - mapear a circulação de obras arquivísticas francesas no Brasil -, desse universo (Tabela 2), selecionamos 334 obras $(1,19 \%$ do total), cujos títulos contemplavam os arquivos e/ou a Arquivologia explicitamente e que tivessem sido publicadas na França. Assim, consideramos obras de autores de diferentes nacionalidades, mas que também circularam naquele país.

Como em nosso mapeamento as obras publicadas na França representam pouco mais de um por cento do total de obras inicialmente identificadas no catálogo on-line do AN, mantivemos todas elas e não as filtramos como Marques (2011) o fez.

\section{RESULTADOS SOB UMA ANÁLISE COMPARATIVA}

Em sua pesquisa, Marques (2011) considerou apenas os livros, que, de acordo com a sua análise, foram predominantemente publicados nas décadas de 1970 e 1980 (Tabela 3), nos Estados Unidos, na França, na Espanha, no Canadá, no Reino Unido, na Itália e no México (Tabela 4).

Tabela 3 - Períodos de publicação das obras arquivísticas estrangeiras (2011)

\begin{tabular}{ccc}
\hline PERÍODO & F & $\%$ \\
\hline séc. XVIII & 2 & 0,65 \\
Séc. XIX & 6 & 1,94
\end{tabular}




\begin{tabular}{ccc}
$1910-1920$ & 1 & 0,32 \\
$1921-1930$ & 8 & 2,58 \\
$1931-1940$ & 7 & 2,26 \\
$1941-1950$ & 9 & 2,9 \\
$1951-1960$ & 8 & 2,58 \\
$1961-1970$ & 22 & 7,1 \\
$1971-1980$ & 61 & 19,68 \\
$1981-1990$ & 83 & 26,77 \\
$1991-2000$ & 55 & 17,74 \\
$2001-2009$ & 25 & 8,06 \\
Data imprecisa & 11 & 3,55 \\
Sem data & 12 & 3,87 \\
\hline TOTAL & 310 & 100 \\
\hline
\end{tabular}

Fonte: (MARQUES, 2011, p. 256).

Em sua análise, a autora lembra que os anos 1970 e 1980 marcaram a Arquivologia internacional, com o redimensionamento do pensamento arquivístico, do qual a visão integrada dos arquivos é um exemplo (ROUSSEAU; COUTURE, 1998). Com exceção do México, ela aponta que os outros países que mais contemplaram as publicações analisadas possuem tradições arquivísticas consolidadas e com grande repercussão no mundo por meio de manuais científicos e operacionais.

Tabela 4 - Países de publicação das obras arquivísticas estrangeiras (2011)

\begin{tabular}{lcc}
\hline PAís DE PUBLICAÇÃO & F & $\%$ \\
\hline Estados Unidos & 79 & 25,48 \\
França & 52 & 16,77 \\
Espanha & 35 & 11,29 \\
Canadá & 22 & 7,1 \\
México & 21 & 6,77 \\
Reino Unido & 21 & 6,77 \\
Itália & 20 & 6,45 \\
Portugal & 8 & 2,58 \\
Bélgica & 6 & 1,94 \\
Argentina & 5 & 1,61 \\
Peru & 5 & 1,61 \\
Austrália & 3 & 0,97 \\
Colômbia & 3 & 0,97 \\
Equador & 3 & 0,97 \\
Rússia & 3 & 0,97 \\
Alemanha & 2 & 0,65 \\
Costa Rica & 2 & 0,65 \\
República Dominicana & 2 & 0,65 \\
Venezuela & 2 & 0,65 \\
Chile & 1 & 0,32 \\
China & 1 & 0,32 \\
Cuba & 1 & 0,32
\end{tabular}




\begin{tabular}{lcc}
\hline \multicolumn{1}{c}{ PAÍS DE PUBLICAÇÃO } & F & $\%$ \\
\hline Holanda & 1 & 0,32 \\
Malásia & 1 & 0,32 \\
Polônia & 1 & 0,32 \\
Suíça & 1 & 0,32 \\
Publicações multinacionais & 3 & 0,97 \\
País não identificado & 6 & 1,94 \\
\hline TOTAL & 310 & 100 \\
\hline
\end{tabular}

Fonte: (MARQUES, 2011, p. 256).

Em nossa pesquisa, verificamos que a maioria (44,91\%) dos 334 livros foi publicada nos anos 1980 (Tabela 5), semelhantemente à pesquisa de Marques (2011). Entretanto, diferentemente da autora, selecionamos somente as obras publicadas na França e, nesse universo mantivemos todas as obras identificadas no catálogo da biblioteca do AN. Assim, não cabe aqui a análise por países, mas por cidades. Paris se destacou com mais de $90 \%$ das publicações (Tabela 6).

Tabela 5 - Períodos das obras arquivísticas publicadas na França (2018)

\begin{tabular}{ccc}
\hline PERÍODO & F & $\%$ \\
\hline Séc. XIII & 2 & 0,60 \\
Séc. XIX & 10 & 2,99 \\
{$[19-]$} & 8 & 2,40 \\
$1901-1910$ & 1 & 0,30 \\
$1911-1920$ & 0 & 0,00 \\
$1921-1930$ & 1 & 0,30 \\
$1931-1940$ & 7 & 2,10 \\
$1941-1950$ & 1 & 0,30 \\
$1951-1960$ & 13 & 3,89 \\
$1961-1970$ & 13 & 3,89 \\
$1971-1980$ & 48 & 14,37 \\
$1981-1990$ & 150 & 44,91 \\
$1991-2000$ & 63 & 18,86 \\
{$[2008]$} & 1 & 0,30 \\
$2001-2010$ & 15 & 4,49 \\
$2011-2018$ & 1 & 0,30 \\
\hline TOTAL & 334 & 100 \\
\hline
\end{tabular}

Fonte: Elaboração própria.

Sobre os nossos resultados, ao focalizarmos a França, temos a publicação da Lei de Arquivos no país, no final da década de 1970 (FRANCE, 1979). Essa lei, acompanhada da descentralização administrativa dos serviços públicos franceses certamente demandaria uma produção que atendesse aos seus desafios, o que pode ter culminado na publicação de um número significativo de obras nos anos 1980, naquele país. E o destaque para Paris, 
provavelmente, se deve por esta ser a sede dos Archives Nationales, do ICA e de vários serviços administrativos do Estado que demandam e produzem tecnicamente na área (dos arquivos).

Tabela 6 - Cidades das obras arquivísticas publicadas na França (2018)

\begin{tabular}{lcc}
\hline \multicolumn{1}{c}{ CIDADE } & F & $\%$ \\
\hline Paris & 303 & 90,72 \\
s.I. & 6 & 1,80 \\
[s.I.] & 4 & 1,20 \\
Marselha & 3 & 0,90 \\
[Paris] & 2 & 0,60 \\
Créteil & 2 & 0,60 \\
Le Mans & 2 & 0,60 \\
Paris; Bogotá & 1 & 0,30 \\
Strasbourg & 1 & 0,30 \\
Rouen & 1 & 0,30 \\
La Garenne & & \\
Colombes (Seiné) & 1 & 0,30 \\
Grenoble & 1 & 0,30 \\
Paris; Rome & 1 & 0,30 \\
Mancha & 1 & 0,30 \\
Fontaine-bleau & 1 & 0,30 \\
Bordeaux & 1 & 0,30 \\
Vincennes & 1 & 0,30 \\
Nanterre & 1 & 0,30 \\
Évreux & 1 & 0,30 \\
\hline Total & 334 & 100 \\
\hline
\end{tabular}

Fonte: Elaboração própria.

Quanto ao idioma, não tivemos informações precedentes para comparar àquelas do nosso levantamento, no qual observamos que $68,86 \%$ das obras sobre arquivos e/ou Arquivologia publicadas na França estavam em francês, certamente por esta ser a sua língua materna. Como também identificamos várias publicações da UNESCO e do ICA, o inglês e o espanhol são recorrentes nessas publicações (com 17,37\% e 11,98\%, respectivamente), conforme Tabela 7.

Tabela 7 - Idiomas das obras arquivísticas publicadas na França (2018)

\begin{tabular}{ccc}
\hline Idiomas & F & $\%$ \\
\hline Francês & 230 & 68,86 \\
Inglês & 58 & 17,37 \\
Espanhol & 40 & 11,98 \\
Inglês/Francês & 4 & 1,20 \\
Trilingue $^{*}$ & 1 & 0,30
\end{tabular}




\begin{tabular}{ccc} 
Inglês/Francês/Espanhol/Árabe & 1 & 0,30 \\
\hline Total & 334 & 100 \\
\hline
\end{tabular}

Fonte: Elaboração própria.

* Tal como aparece no catálogo da biblioteca.

Marques (2011) não nos apresenta, também, uma análise mais detalhada das obras quanto aos tipos bibliográficos. Verificamos, em nossa pesquisa, que, embora no catálogo da biblioteca do $\mathrm{AN}$ as obras estejam classificadas como "livro" ou "livro raro", há uma diversidade de tipos, conforme Tabela 8. Os instrumentos de pesquisa lideram com mais de $40 \%$ do total, seguidos dos livros (26,65\%), que abrangem diversas questões de interesse dos arquivos e da Arquivologia. As publicações técnicas aparecem na terceira posição, com $24,25 \%$ do total, e se relacionam, sobretudo, ao RAMP da UNESCO. Se, no primeiro caso, observamos publicações decorrentes da descrição arquivística de determinados fundos e documentos, no segundo e no terceiro casos temos publicações nacionais e internacionais de especialistas de assuntos variados que afetam os arquivos.

Tabela 8 - Tipos bibliográficos das obras arquivísticas publicadas na França (2018)

\begin{tabular}{lcc}
\hline \multicolumn{1}{c}{ Tipo bibliográfico } & F & $\%$ \\
\hline Instrumento de pesquisa & 142 & 42,51 \\
Livro & 89 & 26,65 \\
Publicação técnica & 81 & 24,25 \\
Documento administrativo & 6 & 1,80 \\
Evento & 5 & 1,50 \\
Legislação & 5 & 1,50 \\
Material de divulgação & 2 & 0,60 \\
Norma & 2 & 0,60 \\
Terminologia arquivística & 1 & 0,30 \\
\hline Total & 334 & 100 \\
\hline
\end{tabular}

Fonte: Elaboração própria.

Nesta tabela, nos chama a atenção a diversidade de aspectos tratados nas obras que mapeamos como "livros", conforme a identicação da própria Biblioteca. Na Tabela 9, apresentamos a sua classificação temática segundo Marques (2011), adotada nesta pesquisa. 
Tabela 9 - Temáticas dos livros arquivísticos publicados na França (2018)

\begin{tabular}{|c|c|c|}
\hline Temáticas & $\mathbf{F}$ & $\%$ \\
\hline Livro (acesso) & 1 & 1,12 \\
\hline Livro (aquisição) & 1 & 1,12 \\
\hline Livro (arquivo e história) & 1 & 1,12 \\
\hline Livro (arquivo intermediário) & 2 & 2,25 \\
\hline Livro (Arquivo) & 2 & 2,25 \\
\hline Livro (arquivos empresariais) & 2 & 2,25 \\
\hline Livro (arquivos históricos) & 1 & 1,12 \\
\hline Livro (arquivos institucionais) & 4 & 4,49 \\
\hline Livro (arquivos nacionais) & 1 & 1,12 \\
\hline Livro (arquivos públicos) & 2 & 2,25 \\
\hline Livro (arquivos) & 4 & 4,49 \\
\hline Livro (automação) & 2 & 2,25 \\
\hline Livro (avaliação) & 1 & 1,12 \\
\hline Livro (bibliografia) & 1 & 1,12 \\
\hline Livro (classificação e conservação) & 2 & 2,25 \\
\hline Livro (classificação) & 3 & 3,37 \\
\hline Livro (comitê) & 1 & 1,12 \\
\hline Livro (conservação e restauração) & 1 & 1,12 \\
\hline Livro (conservação) & 6 & 6,74 \\
\hline Livro (contencioso) & 1 & 1,12 \\
\hline Livro (cooperação internacional) & 2 & 2,25 \\
\hline Livro (descrição) & 2 & 2,25 \\
\hline Livro (diagnóstico) & 5 & 5,62 \\
\hline Livro (difusão) & 1 & 1,12 \\
\hline Livro (Diplomática) & 1 & 1,12 \\
\hline Livro (documentos eletrônicos) & 2 & 2,25 \\
\hline Livro (documentos públicos) & 1 & 1,12 \\
\hline Livro (formação) & 6 & 6,74 \\
\hline Livro (função do arquivo e política do arquivo) & 1 & 1,12 \\
\hline Livro (função do arquivo) & 1 & 1,12 \\
\hline Livro (gênero documental) & 1 & 1,12 \\
\hline Livro (gestão de documentos) & 1 & 1,12 \\
\hline Livro (instalações de arquivos e equipamentos) & 1 & 1,12 \\
\hline Livro (instalações e equipamentos) & 1 & 1,12 \\
\hline Livro (instalações) & 5 & 5,62 \\
\hline Livro (legislação) & 1 & 1,12 \\
\hline Livro (manual) & 6 & 6,74 \\
\hline Livro (memória) & 2 & 2,25 \\
\hline Livro (orientações) & 1 & 1,12 \\
\hline Livro (paleografia) & 1 & 1,12 \\
\hline Livro (pesquisa histórica) & 1 & 1,12 \\
\hline Livro (política de harmonização) & 2 & 2,25 \\
\hline Livro (preservação e conservação) & $\overline{1}$ & 1,12 \\
\hline Livro (preservação) & 1 & 1,12 \\
\hline Livro (profissão) & 1 & 1,12 \\
\hline Livro (sistemas de informação) & 2 & 2,25 \\
\hline Total & 89 & 100 \\
\hline
\end{tabular}

Fonte: Elaboração própria. 
No seu universo de análise, Marques (2011) observou que 32 autores eram recorrentes. Desses, ela excluiu as autorias institucionais, chegando a 21 autores com as seguintes origens institucionais, isto é, seus vínculos profissionais: a) cinco dos Estados Unidos; b) cinco da Inglaterra; c) quatro da Espanha; d) três do Canadá; e) um da França; f) um de Portugal; g) um da Argentina; e h) um do Equador (Tabela 11). A estudiosa destacou a baixa frequência de autores franceses, levando em consideração o papel da França na trajetória da Arquivologia mundial e relacionou a presença de autores norteamericanos, ingleses, espanhóis e canadenses aos avanços do pensamento arquivístico internacional quanto à gestão de documentos, ao papel do arquivista e dos arquivos nas instituições, aos estudos de tipologia documental e à integração dos arquivos administrativos e históricos.

\section{Tabela 11 - Autores recorrentes das obras arquivísticas estrangeiras} (2011)

\begin{tabular}{lcc}
\hline AUTORES RECORRENTES NAS OBRAS INTERNACIONAIS & F & $\%$ \\
\hline DIRECCION DES ARCHIVES DE FRANCE & 11 & 10,48 \\
NARS (Estados Unidos) & 9 & 8,57 \\
PUBLIC ARCHIVES CANADA & 8 & 7,72 \\
ICA & 6 & 5,61 \\
ARCHIVO GENERAL DE LA NACION (México) & 5 & 4,76 \\
ALBERCH I FUGUERAS, Ramón & 4 & 3,81 \\
COOK, Michael & 4 & 3,81 \\
CORTÉS ALONSO, Vicenta & 4 & 3,81 \\
DUCHEIN, Michel & 4 & 3,81 \\
SCHELLENBERG, Theodore Roosevelt & 4 & 3,81 \\
ARCHIVI DI STATO (Itália) & 3 & 2,86 \\
EVANS, Frank B. & 3 & 2,86 \\
ARCHIVAL RESEARCH AND EVOLUTION STAFF & 2 & 1,9 \\
ARCHIVES PUBLIQUES DU CANADÁ & 2 & 1,9 \\
BUCHANAN, Sally A. & 2 & 1,9 \\
CAIN, Piers & 2 & 1,9 \\
ESTADOS UNIDOS. War Departament & 2 & 1,9 \\
GOMEZ CANEDO, Lino & 2 & 1,9 \\
HILL, Roscoe R. & 2 & 1,9 \\
JENKINSON, Hilary & 2 & 1,9 \\
LANGE, Jane W. & 2 & 1,9 \\
MILLAR, Laura & 2 & 1,9 \\
NARA [Estados Unidos] & 2 & 1,9 \\
PESCADOR DEL HOYO, Maria del Carmen & 2 & 1,9 \\
ROBERGE, Michel & 2 & 1,9 \\
ROPER, Michael & 2 & 1,9 \\
ROUSSEAU, Jean Yves & 2 & 1,9 \\
COUTURE, Carol & 2 & 1,9 \\
RIBEIRO, Fernanda & 2 & 1,9
\end{tabular}




\begin{tabular}{lcc}
\hline AUTORES RECORRENTES NAS OBRAS INTERNACIONAIS & F & $\%$ \\
\hline TANODI, Aurélio & 2 & 1,9 \\
THE ROYAL COMMISSION ON HISTORICAL MANUSCRIPTS & 2 & 1,9 \\
(Inglaterra) & 2 & 1,9 \\
VASCO DE ESCUDERO, Grecia & 105 & 100 \\
\hline TOTAL
\end{tabular}

Fonte: (MARQUES, 2011, p. 257).

Localizamos 379 autores, dos quais aproximadamente 120 (67\%) ${ }^{6}$ eram reincidentes (Tabela 12). Mais de $25 \%$ das obras estão concentradas em três autores institucionais (Archives Nacionales, Direction des Archives de France e ICA). Ainda é interessante observar que foi possível identificar dez obras (2,64\%) de franceses que contribuíram para a institucionalização da Arquivologia brasileira (Michel Duchein, Bruno Delmas, Charles Kecskeméti e Ivan Cloulas), conforme nosso projeto de pesquisa maior a respeito.

Tabela 12 - Autores recorrentes das obras arquivísticas publicadas na França (2018)

\begin{tabular}{lcc}
\hline \multicolumn{1}{c}{ Autor } & F & $\%$ \\
\hline ARCHIVES NATIONALES (França) & 55 & 14,51 \\
DIRECTION DES ARCHIVES DE FRANCE & 21 & 5,54 \\
INTERNATIONAL COUNCIL ON ARCHIVES & 21 & 5,54 \\
HILDESHEIMER, Francoise & 6 & 1,58 \\
UNESCO & 5 & 1,32 \\
RHOADS, James B. & 4 & 1,06 \\
FAVIER, Jean & 4 & 1,06 \\
DUCHEIN, Michel & 4 & 1,06 \\
BIMBENET-PRIVAT, Michèle & 4 & 1,06 \\
ARCHIVES DÉPARTEMENTALES (Val-de-Marne, FR) & 4 & 1,06 \\
GOTTERI, Nicole & 4 & 1,06 \\
BUCHANAN, Sally A. & 4 & 1,06 \\
ROPER, Michael & 4 & 1,06 \\
KATHPALIA, Yash Pal & 3 & 0,79 \\
CHARON BORDAS, Jeannine & 3 & 0,79 \\
MAZIKANA, Peter C. & 3 & 0,79 \\
THOMAS, D. L. & 3 & 0,79 \\
COOK, Michael & 3 & 0,79 \\
DIRECCION DES ARCHIVES DE FRANCE & 3 & 0,79 \\
LEARY, William & 3 & 0,79 \\
BABELON, Jean-Pierre & 3 & 0,79 \\
ARCHIVES DEPARTEMENTALES, BOUCHES-DU-RHONE & 3 & 0,79 \\
CENTRE DE RECHERCHE SUR LA CONSERVATION DES & 3 & 0,79 \\
DOCUMENTS GRAPHIQUES & 3 & 0,79 \\
CUNHA, George Martin & &
\end{tabular}

${ }^{6}$ Este número é aproximado, porque não foi possível identificarmos a nacionalidade de 10 autores (5\% do total). 


\begin{tabular}{|c|c|c|}
\hline Autor & $\mathbf{F}$ & $\%$ \\
\hline DELMAS, Bruno & 3 & 0,79 \\
\hline GROLIER, Eric de & 3 & 0,79 \\
\hline LEE, Mary Wood & 2 & 0,53 \\
\hline FONTAINE, France & 2 & 0,53 \\
\hline NEIRINCK, Daniele & 2 & 0,53 \\
\hline ARCHIVES DÉPARTEMENTALES (Seine-Maritime, FR) & 2 & 0,53 \\
\hline GALLET GUERNE, Danielle & 2 & 0,53 \\
\hline GREEN, Adam & 2 & 0,53 \\
\hline MOSS, William W. & 2 & 0,53 \\
\hline BERNARD, Gildas & 2 & 0,53 \\
\hline PARKER, Thomas A. & 2 & 0,53 \\
\hline WALNE, Peter & 2 & 0,53 \\
\hline TANODI, Aurélio & 2 & 0,53 \\
\hline HARRISON, Helen P. & 2 & 0,53 \\
\hline ULATE SEGURA, Bodil & 2 & 0,53 \\
\hline HENDRIKS, Klaus B. & 2 & 0,53 \\
\hline EVANS, Frank B. & 2 & 0,53 \\
\hline CORTES ALONSO, Vicenta & 2 & 0,53 \\
\hline NAUGLER, Harold & 2 & 0,53 \\
\hline KECSKEMETI, Charles & 2 & 0,53 \\
\hline OLIER, J. H. & 2 & 0,53 \\
\hline KITCHING, Christopher & 2 & 0,53 \\
\hline BERNHARD, Paulette & 2 & 0,53 \\
\hline KRAKOVITCH, Odile & 2 & 0,53 \\
\hline STARK, Marie Charlotte & 2 & 0,53 \\
\hline LAMUR-BAUDREU, Anne-Claude & 2 & 0,53 \\
\hline TAYLOR, Hugh A. & 2 & 0,53 \\
\hline LANGLOIS, Monique & 2 & 0,53 \\
\hline TOURTIER-BONAZZI, Chantal de & 2 & 0,53 \\
\hline LE MOËL, Geneviève & 2 & 0,53 \\
\hline GERBAUD, Henri & 2 & 0,53 \\
\hline et al & 2 & 0,53 \\
\hline GUERIN-BROT, Isabelle & 2 & 0,53 \\
\hline ARCHIVES DÉPARTEMENTALES (Sarthe, FR) & 2 & 0,53 \\
\hline Autores não recorrentes & 136 & 35,88 \\
\hline Total & 379 & 100 \\
\hline
\end{tabular}

Fonte: Elaboração própria.

Das 310 obras arquivísticas estrangeiras identificadas pela estudiosa, 32 foram reeditadas, reimpressas ou traduzidas. Quanto às traduções brasileiras para o português de obras estrangeiras, ela identificou 12, das quais três eram de obras francesas, conforme Quadro 1.

Quadro 1 - Traduções brasileiras de obras arquivísticas estrangeiras (2011)

\begin{tabular}{|l|l|c|}
\hline \multicolumn{1}{|c|}{ AUTOR } & \multicolumn{1}{|c|}{ OBRA } & $\begin{array}{c}\text { ANO DA } \\
\text { TRADUÇÃO }\end{array}$ \\
\hline WHITE, E. W. & Arquivar e achar & 1941 \\
\hline SCHELLENBERG, T. R. & Manual de Arquivos & 1959 \\
\hline
\end{tabular}




\begin{tabular}{|c|c|c|}
\hline AUTOR & OBRA & $\begin{array}{l}\text { ANO DA } \\
\text { TRADUÇÃO }\end{array}$ \\
\hline SCHELLENBERG, T. R. & $\begin{array}{l}\text { A avaliação dos documentos públicos } \\
\text { modernos }\end{array}$ & 1959 \\
\hline $\begin{array}{l}\text { MULLER, S.; FEITH, J. A.; } \\
\text { FRUIN, R. }\end{array}$ & $\begin{array}{l}\text { Manual de arranjo e descrição de } \\
\text { arquivos }\end{array}$ & 1960 \\
\hline SCHELLENBERG, T. R. & $\begin{array}{l}\text { Documentos públicos e privados: arranjo } \\
\text { e descrição }\end{array}$ & 1963 \\
\hline SABBE, E. & Os Arquivos de Estado & 1963 \\
\hline JAMESON, S. H. & $\begin{array}{l}\begin{array}{l}\text { Administração } \\
\text { documentação }\end{array} \\
\text { de }\end{array}$ & 1964 \\
\hline VALETTE, J. J, & $\begin{array}{l}\text { O papel dos arquivos na administração e } \\
\text { na política de planificação nos países em } \\
\text { desenvolvimento }\end{array}$ & 1973 \\
\hline SCHELLENBERG, T. R. & Arquivos Modernos: princípios e técnicas & 1973 \\
\hline DUBOSCQ, G. & Organização do pré-arquivo & 1974 \\
\hline [CANADÁ] & $\begin{array}{l}\text { Arquivos correntes: organização e } \\
\text { funcionamento }\end{array}$ & 1975 \\
\hline CLAYBROOK, Billy G. & Técnicas de gerenciamento de arquivos & 1987 \\
\hline
\end{tabular}

Fonte: Marques (2011, p. 258).

Em nossa pesquisa, não localizamos traduções de obras, pois, conforme mencionado, aquelas do RAMP foram originalmente publicadas em mais de um idioma, o que não caracteriza tradução de uma edição diferente.

Mediante a análise do seu mapeamento de obras arquivísticas estrangeiras, brasileiras e traduzidas para o português, na biblioteca do AN, Marques (2011) concluiu que há uma amostra significativa da produção arquivística mundial em circulação no Brasil. Embora o número de traduções fosse relativamente pequeno, ela realçou a qualidade e a repercussão dessas obras, como possibilidades de reinscrição do discurso arquivístico, a exemplo das reedições e reimpressões que também refletem essa repercussão.

A autora observou, ainda, o progressivo aumento dessas publicações, concentradas nos últimos anos, com a atuação de autores pessoais e institucionais, ressaltando o importante papel das instituições arquivísticas, dos conselhos e das associações nos avanços da área. Quanto aos autores estrangeiros, ela destacou as contribuições de vários que visitaram o Brasil a partir do final da década de 1950 (espanhóis, franceses, norte-americanos, argentinos, etc.), colaborando para a organização dos arquivos brasileiros e para a institucionalização da Arquivologia no país.

No quadro 2, apresentamos uma síntese comparativa das duas pesquisas 
que, embora tenham especificidades de acordo com os seus distintos objetivos, partiram do mesmo universo de análise.

Quadro 2 - Indicadores predominantes nas obras arquivísticas da biblioteca do AN

\begin{tabular}{|l|l|l|}
\hline ASPECTO ANALISADO & \multicolumn{1}{|c|}{2011} & \multicolumn{1}{c|}{2018} \\
\hline Universo & $\begin{array}{l}310 \text { livros (excluídos os os } \\
\text { demais tipos bibliográficos } \\
\text { após a análise), publicados } \\
\text { internacionalmente }\end{array}$ & $\begin{array}{l}334 \text { livros (mantidos os } \\
\text { demais tipos bibliográficos } \\
\text { após a análise), } \\
\text { publicados na França }\end{array}$ \\
\hline Períodos & 1970 e 1980 & 1980 \\
\hline Países ou cidades & \multicolumn{1}{|c|}{ Português } & Paris \\
\hline Idioma & \multicolumn{1}{|c|}{-} & Francês \\
\hline Tipos bibliográficos & $\begin{array}{l}\text { Norte-americanos } \\
\text { ingleses (considerados } \\
\text { somente os autores } \\
\text { pessoais) }\end{array}$ & $\begin{array}{l}\text { Franceses e com sede na } \\
\text { França (considerados os } \\
\text { autores institucionais) }\end{array}$ \\
\hline Autores recorrentes & &
\end{tabular}

Fonte: Elaboração própria.

\section{CONSIDERAÇÕES FINAIS}

Ao tomarmos por base uma pesquisa realizada há nove anos, esperávamos ter resultados semelhantes (considerando o mesmo universo de coleta dos dados, atualizado, o acervo da biblioteca do AN), mas também vislumbrávamos singularidades, em razão do recorte feito para este trabalho: livros sobre arquivos e/ou Arquivologia publicados na França.

De fato, observamos que parte do período apontado na primeira pesquisa permaneceu em destaque, a década de 1980, período de movimentos e repercussões no cenário arquivístico francês em razão da promulgação da Lei de Arquivos no País. Certamente, isto repercutiria na demanda por estudos e, consequentemente, pela publicação de obras que dessem conta dos desafios desse novo contexto. Por ser a capital administrativa da França e por sediar instituições internacionais como a UNESCO e o ICA, Paris centraliza essa produção, que diz respeito, sobretudo, a instrumentos de pesquisa, livros e publicações técnicas que contemplam diversos interesses da Arquivologia e do seu objeto de estudo, os arquivos.

Especificamente quanto aos instrumentos de pesquisa, parece haver uma 
preocupação acerca da sua produção, no sentido de as instituições arquivísticas francesas se dedicarem à descrição dos fundos e documentos por elas custodiados, tendo em vista o seu acesso intelectual. Contudo, é curioso encontrá-los em grande número no acervo da instituição brasileira, que, mesmo se inspirando nos Archives Nationales (como o faz desde a sua criação, no século XIX), certamente há outros tipos de obras que também merecem investimento da instituição. Afinal, o pensamento arquivístico francês continua a ser referência internacional na contemporaneidade e há uma produção de livros significativa.

Os resultados obtidos neste estudo representam um recorte das obras arquivísticas estrangeiras que circulam no Brasil e apresentam indícios de preocupações de instituições nacionais acerca do acompanhamento do desenvolvimento das práticas e dos pensamentos internacionais da Arquivologia, bem como a sua atualização na formação dos seus acervos. Importantes se fazem outros estudos que contemplem outras instituições, outros acervos bibliográficos e outros recortes topográficos que possam ampliar as possibilidades de relacionamentos, análises e reflexões.

\section{REFERÊNCIAS}

ARAÚJO, C. A. Bibliometria: evolução histórica e questões atuais. Em Questão, Porto Alegre, v. 12, n. 1, p. 11-32, jan./jun. 2006.

CUNHA, M. B. da; CAVALCANTI, C. R. de O. Dicionário de Biblioteconomia e Arquivologia. Brasília: Brinquet de Lemos, 2008.

FONSECA, M. O. K. Publicações técnicas do Arquivo Nacional. Acervo, Rio de Janeiro, v. 3, n. 2, jul./dez. 1988, p. 101-110.

FRANCE. Loi nº 79-18 du 3 janvier 1979 sur les archives. Gazette des archives, 104, 1979, p. 34-41.

LARA, M. L. G. Glossário: termos e conceitos da área de comunicação e produção científica. In: POBLACION, D. A.; WITTER, G. P.; SILVA, J. F. M. (Org.). Comunicação e produção científica: contexto, indicadores, avaliação. São Paulo: Angellara, 2006.

MARQUES, A. A. da C. Interlocuções entre a arquivologia nacional e a internacional no delineamento da disciplina no Brasil. 2011. 399 f. Tese 
(Doutorado em Ciência da Informação) - Universidade de Brasília, Brasília, 2011. Disponível em: https://repositorio.unb.br/handle/10482/8730.

PINHEIRO, A. V. Livro raro: antecedentes, propósitos e definições. In: SILVA, H. de C.; BARROS, M. H. T. C. de (Org.) Ciência da Informação: múltiplos diálogos. Marília: Oficina Universitária Unesp, 2009.

RODRIGUES, M. C. Como definir e identificar obras raras? Critérios adotados pela Biblioteca Central da Universidade de Caxias do Sul. Ciência da Informação, Brasília, v. 35, n. 1, p. 115-121, jan./abr. 2006

ROSTIROLLA, G. Bibliometria como tema de tese: análise a partir da biblioteca digital de teses e dissertações. In: ENCONTRO BRASILEIRO DE BIBLIOMETRIA E CINETOMETRIA, 4., 2014, Recife. Anais [...]. Recife: UFPE, 2014. Disponível em: http://www.brapci.inf.br/index.php/article/download/27246. Acesso em: 29 jun. 2019.

ROUSSEAU, Jean-Yves; COUTURE, C. Os fundamentos da disciplina arquivística. Tradução de Magda Bigotte de Figueiredo. Lisboa: Publicações Dom Quixote, 1998.

ZAUITH, G.; HAYASHI, M. C. P. I. A influência de Paulo Freire no ensino de ciências e na educação CTS: Uma análise bibliométrica. Revista HISTEDBR On-line, Campinas, n. 49, p. 267-293, 2013. Disponível em: https://periodicos.sbu.unicamp.br/ojs/index.php/histedbr/article/view/8640332/7 891.

\title{
CIRCULATION OF FRENCH ARCHIVAL WORKS IN BRAZIL
}

\begin{abstract}
Introduction: This article is part of the research project on the trajectory of the internationalization of Archival Science and its institutionalization as a discipline in BrazilObjective: Investigate French contributions to Brazlian Archival Science, through the circulation on French archival works in Brazil. Methodology: Qualitative-quantitative approach research; exploratory and descriptive, regarding its objectives; bibliographical and documentary, through a bibliometric study comparative of the books about archives and / or Archival Science, identified in the online catalog of the National Archive library. Results: The analysis of 334 archival works identified as books in the AN library in this catalog pointed out that most of these works were published in the 1980s in Paris and in French. They are mostly of research instruments, books and technical publications produced by authors from French nationality or who have their headquarters in the country, in the case of international institutions. Conclusions: The analyzed universe concernsto recent works, about several archival questions, including in the international perspective, what can justify its circulation in Brazil. No clear reason was found for the acquisition of a significant amount of research instruments from French institutions, by National Archive. Even though the Brazilian institution get inspired by the French institution, there are other types of works that deserve the institution's investment looking
\end{abstract}


at the reference of French archival thinking, even in contemporary times.

Descriptors: Archival Science; archives; archival bibliography; archival books; circulation of French works.

\title{
CIRCULACIÓN DE OBRAS ARCHIVÍSTICAS FRANCESAS EN BRASIL
}

\begin{abstract}
RESUMEN
Introducción: Este articulo integra el proyecto de investigación sobre la trayectoria de la internacionalización de la Archivología y su institucionalización como disciplina en Brasil. Objetivo: Investigar las contribuciones francesas para la archivología brasileña, por medio de la circulación de obras archivísticas en Brasil. Metodología: Investigación cuali-cuantitativa, de abordaje exploratoria y descriptiva en relación a sus objetivos; bibliográfica y documental, por medio de un estudio bibliométrico de los libros sobre archivos yo archivología, identificados en el catálogo on-line de la biblioteca del Archivo Nacional. Resultados: el análisis de 334 obras archivísticas identificadas como libros en el catálogo apuntaron que la mayoría de esas obras fueron publicadas en la década de 1980, en Paris y en francés. Tratase predominantemente de instrumentos de investigación, libros y publicaciones técnicas producidas por autores de nacionalidad francesa o que tenían sede en Francia, en el caso de instituciones internacionales. Conclusiones: $O$ universo analizado dice al respecto a las obras recientes, sobre cuestiones archivísticas diversas, inclusive en le perspectiva internacional, lo que puede justificar su circulación en Brasil. No fue encontrado una razón evidente para la adquisición de una cantidad significativa de instrumentos de investigación de instituciones francesas, por la Archivo Nacional. Sea que la institución brasileña se inspire en la francesa, hay otros tipos de obras que merecen inversión de la institución teniendo en cuenta la referencia del pensamiento archivístico francés, inclusive en la contemporaneidad.
\end{abstract}

Descriptores: Archivologia. Bibliografía archivistica. Libros archivisticos. Circulación de obras francesas.

Recebido em: 26.03.2020

Aceito em: 08.02.2021 